\title{
RNAi-mediated serotonin transporter suppression rapidly increases serotonergic neurotransmission and hippocampal neurogenesis
}

\author{
A Ferrés-Coy ${ }^{1,2}$, F Pilar-Cuellar ${ }^{2,3}$, R Vidal ${ }^{2,3}$, V Paz $^{1,2}$, M Masana $^{1,2,7}$, R Cortés $^{1,4}$, MC Carmona $^{5}$, L Campa ${ }^{1,2}$, Á Pazos $^{2,3}$, \\ A Montefeltro ${ }^{5}$ EM Valdizán ${ }^{2,3}, \mathrm{~F}_{\text {Artigas }}{ }^{1,2}$ and A Bortolozzi ${ }^{1,2,6}$
}

Current antidepressants, which inhibit the serotonin transporter (SERT), display limited efficacy and slow onset of action. Here, we show that partial reduction of SERT expression by small interference RNA (SERT-siRNA) decreased immobility in the tail suspension test, displaying an antidepressant potential. Moreover, short-term SERT-siRNA treatment modified mouse brain variables considered to be key markers of antidepressant action: reduced expression and function of $5-\mathrm{HT}_{1 \mathrm{~A}}$-autoreceptors, elevated extracellular serotonin in forebrain and increased neurogenesis and expression of plasticity-related genes (BDNF, VEGF, Arc) in hippocampus. Remarkably, these effects occurred much earlier and were of greater magnitude than those evoked by long-term fluoxetine treatment. These findings highlight the critical role of SERT in serotonergic function and show that the reduction of SERT expression regulates serotonergic neurotransmission more potently than pharmacological blockade of SERT. The use of siRNA-targeting genes in serotonin neurons (SERT, $5-\mathrm{HT}_{1 \mathrm{~A}}$-autoreceptor) may be a novel therapeutic strategy to develop fast-acting antidepressants.

Translational Psychiatry (2013) 3, e211; doi:10.1038/tp.2012.135; published online 15 January 2013

\section{Introduction}

Despite the high prevalence of depression and its considerable socioeconomic impact, its pathophysiological mechanisms remain poorly understood. ${ }^{1-3}$ Serotonin $(5-\mathrm{HT})$ participates in the etiology and treatment of major depression, being the selective serotonin reuptake inhibitors (SSRIs), the most common antidepressant therapy. However, SSRIs need to be administered for long time periods before clinical improvement emerges, and fully remit depressive symptoms in only one third of patients. ${ }^{4-6}$

The serotonin transporter (SERT) is a key regulator of serotonergic neurotransmission, as it controls the active fraction of 5-HT. In the brain, SERT is localized to raphe 5HT neurons at somatodendritic and terminal levels. ${ }^{7-9}$ SERT blockade by SSRIs (showing $\mathrm{nM}$ affinity for SERT) ${ }^{10}$ initiates the chain of events leading eventually to clinical improvement. Long-term SSRI treatment promotes an internalization of SERT from the cell surface in 5-HT neurons without affecting SERT mRNA expression. ${ }^{11-15}$ In addition to loss of $5-\mathrm{HT}_{1 \mathrm{~A}^{-}}$ autoreceptor function, ${ }^{16-18}$ SERT down-regulation may enhance forebrain 5-HT neurotransmission contributing to the therapeutic action of SSRIs. ${ }^{19,20}$

Polymorphic variations in SERT transcriptional regionleading to reduced SERT expression and function-are involved in multiple neuropsychiatric disorders, including major depression, ${ }^{21-25}$ and in the clinical response to SSRI. $^{26,27}$ SERT-knockout mice were generated to gain further insight into the role of SERT in the pathophysiology and treatment of depression. ${ }^{28,29}$ However, these mice showed depression-related behaviors attributable to the developmental changes that result from SERT early-life absence and the perturbed 5-HT function. ${ }^{30-32}$ Thus, while SERT-knockout mice represent a useful model to investigate disorders involving genetic alterations in SERT during early life, they are less appropriate to study downstream changes of 5-HT transmission secondary to SERT blockade in adulthood.

RNA interference (RNAi) has a critical role in regulating gene expression. ${ }^{33,34}$ It also provides new alternatives to pharmacological treatments to modulate brain neurotransmission through the use of exogenous small interference RNA (siRNA). Recent studies have shown the feasibility to silence the expression of critical genes in 5-HT neurons, such as SERT and the $5-\mathrm{HT}_{1 \mathrm{~A}}$-autoreceptor. ${ }^{18,35}$ Given the above limitations of SERT-knockout mice, here we evaluated the specificity and selectivity of partial SERT suppression in adult mice, following short-term SERT-siRNA treatment. We examined downstream changes on brain variables linked to antidepressant efficacy and compared SERT-siRNA effects with those of a standard SSRI (fluoxetine) treatment. The results indicate that the post-transcriptional regulation of

\footnotetext{
${ }^{1}$ Department of Neurochemistry and Neuropharmacology, IIBB-CSIC, IDIBAPS, Barcelona, Spain; ${ }^{2}$ Centro de Investigación Biomédica en Red de Salud Mental (CIBERSAM), ISCIII, Madrid, Spain; ${ }^{3}$ Institute of Biomedicine and Biotechnology of Cantabria (IBBTEC; UC-CISC-SODERCAN), Santander, Spain; ${ }^{4}$ Centro de Investigación Biomédica en Red de Enfermedades Neurodegenerativas (CIBERNED), ISCIII, Madrid, Spain; ${ }^{5}$ Life Therapeutics, S.L., Granada, Spain and ${ }^{6}$ Institut d'Investigacions Biomèdiques August Pi i Sunyer (IDIBAPS), Barcelona, Spain

Correspondence: Dr A Bortolozzi, Deparment of Neurochemistry and Neuropharmacology, IIBB-CSIC-IDIBAPS, Barcelona 08036, Spain.

E-mail: abbnqi@iibb.csic.es

${ }^{7}$ Current address: Max Planck Institute of Psychiatry, Munich D-80804, Germany

Keywords: BDNF; fast-acting antidepressants; neurogenesis; RNAi; serotonin; SERT transporter

Received 24 July 2012; revised 8 November 2012; accepted 10 November 2012
} 


$$
2
$$

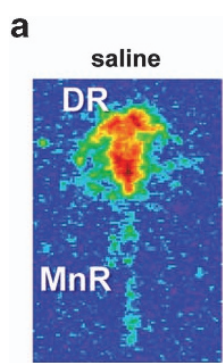

vehicle

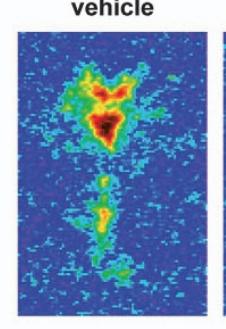

c
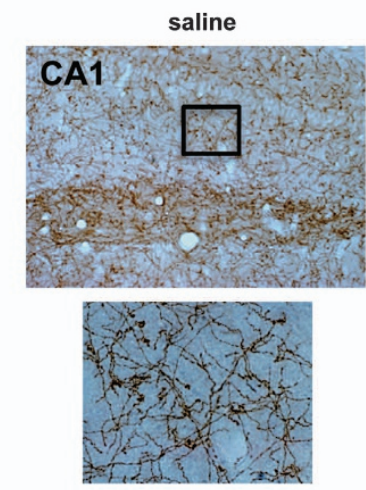

vehicle
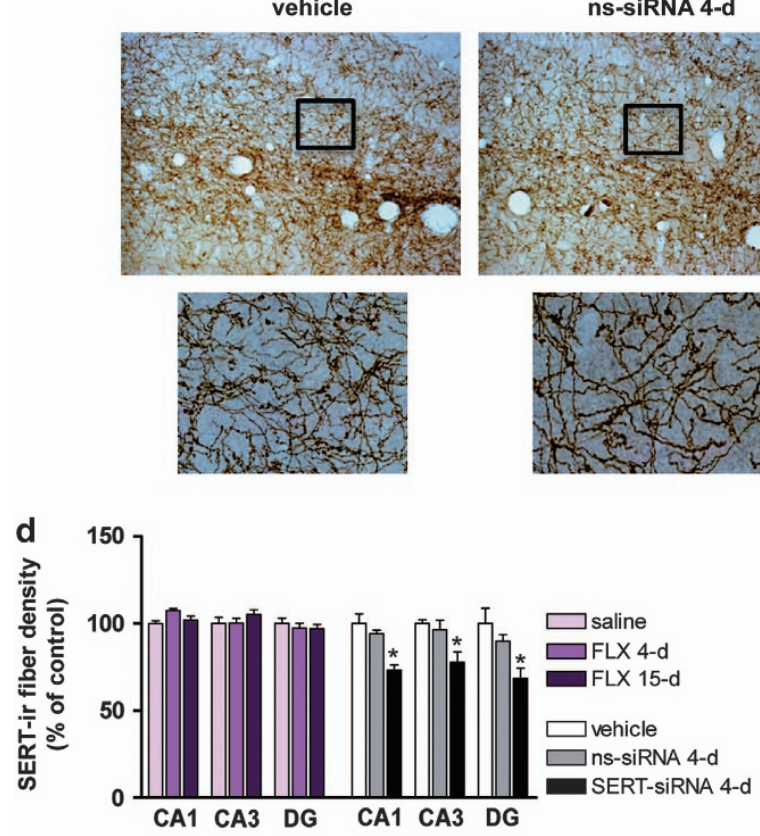

SERT-ir

FLX 4-d
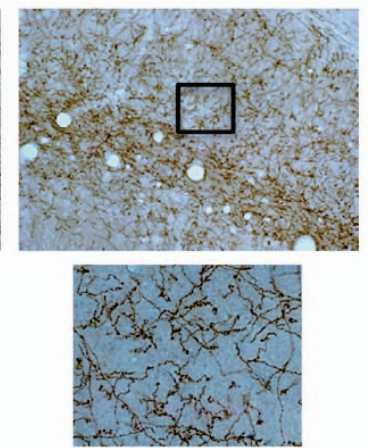

ns-siRNA 4-d
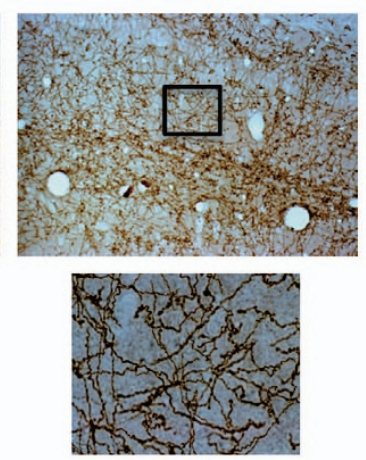

b
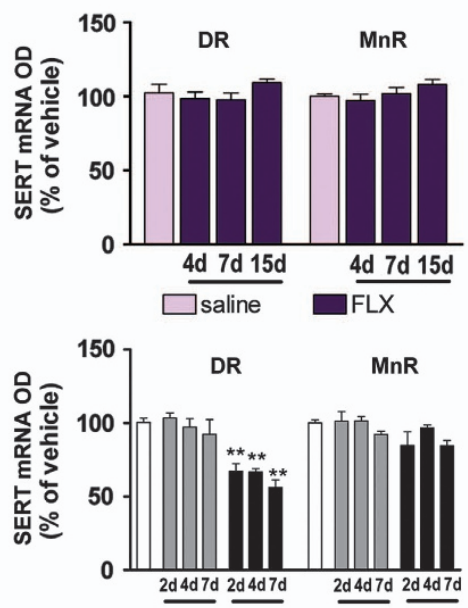

$\square$ vehicle $\square$ SERT-siRNA $\square$ ns-siRNA

FLX 15-d
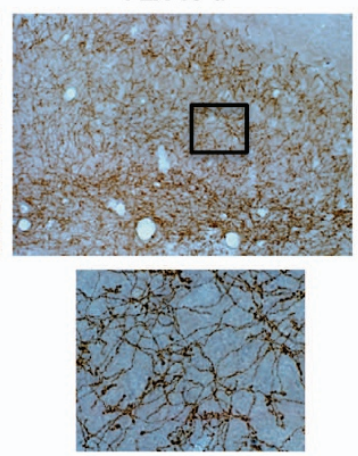

SERT-siRNA 4-d
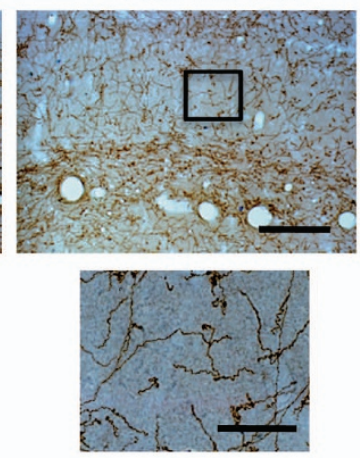

e

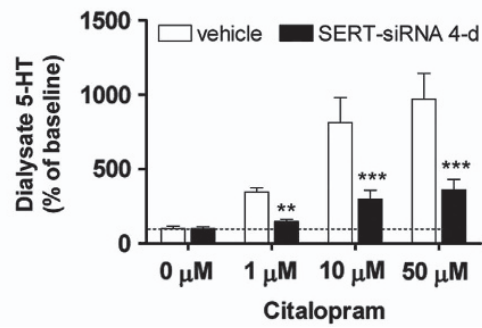


SERT may constitute a target for fast-acting antidepressants, thus bringing RNAi closer to the clinic as a potential therapy for major depression.

\section{Materials and methods}

Animals. Male C57BL/6J mice (10-14 weeks; Charles River, Lyon, France) were housed under controlled conditions $\left(22 \pm 1{ }^{\circ} \mathrm{C} ; 12 \mathrm{~h}\right.$ light/dark cycle) with food and water available ad libitum. Animal procedures were conducted in accordance with standard ethical guidelines (EU regulations L35/118/12/ 1986) and approved by the local ethical committee.

Drug/siRNA treatments. SERT-targeting siRNA (nt:12301250, GenBank accession NM_010484) and an unrelated siRNA with no homology to mouse genome (nonsense siRNA, ns-siRNA) were used (Life Technology, Madrid, Spain). The siRNA sequences are shown in Supplementary Table S1.

Mice were anesthetized (pentobarbital, $40 \mathrm{mg} \mathrm{kg}^{-1}$, intraperitoneally, i.p.) and silica capillary microcannula $(110 \mu \mathrm{m}$ outer diameter (OD), $40 \mu \mathrm{m}$-inner diameter (ID); Polymicro Technologies, Madrid, Spain) were stereotaxically implanted into the dorsal raphe nucleus (DR; coordinates in $\mathrm{mm}$ : anteroposterior, -4.5; mediolateral, - 1.0; dorsoventral, -4.4; with a lateral angle of $\left.20^{\circ}\right) .{ }^{36}$ Local siRNA microinfusion was performed with a perfusion pump at $0.5 \mu \mathrm{min}^{-1} 24 \mathrm{~h}$ after surgery in awake mice as described previously. ${ }^{18}$ siRNAs were prepared in artificial cerebrospinal fluid (125 mM NaCl, $2.5 \mathrm{~mm}$ $\mathrm{KCl}, 1.26 \mathrm{~mm} \mathrm{CaCl}_{2}$ and $1.18 \mathrm{~mm} \mathrm{MgCl}_{2}$ with $5 \%$ glucose) and infused intra-DR once daily at the dose of $10 \mu \mathrm{g} \mathrm{Il}^{-1}(0.7 \mathrm{nmol}$ per dose). Mice received two dose in 2 consecutive days, or four dose in 5 days (days 1, 2, 4 and 5), and were killed on 3rd or 6 th day, respectively. An additional group of mice received seven dose in 9 days (days 1, 2, 3, 5, 6, 8 and 9) and was killed on 10th-day. In the last group, only in situ hybridization and autoradiography studies were performed (see below). Control mice received artificial cerebrospinal fluid.

Fluoxetine (Tocris, Madrid, Spain) was prepared in saline and was administered once daily at $20 \mathrm{mg} \mathrm{kg}^{-1}$ dose, i.p. for 4,7 or 15 days. Mice were killed on 5 th, 8 th or 16 th day, respectively. Control mice received saline.

\section{In situ hybridization and autoradiographic studies}

Tissue preparation. Mice were killed by pentobarbital overdose and brains rapidly removed, frozen on dry ice and stored at $-80^{\circ} \mathrm{C}$. Tissue sections (14 $\mu \mathrm{m}$ thick-coronal) were cut using a microtome-cryostat (HM500-OM, Microm, Walldorf, Germany), thaw-mounted onto 3-aminopropyltriethoxysilane (Sigma-Aldrich, Madrid, Spain)-coated slides and kept at $-20^{\circ} \mathrm{C}$ until use.

In situ hybridization. Antisense oligoprobes $\left[{ }^{33} \mathrm{P}\right]$-labeling and in situ hybridization procedures were carried out as described previously. ${ }^{18}$ Mouse SERT, 5- $\mathrm{HT}_{1 \mathrm{~A}} \mathrm{R}$, tryptophan hydroxylase 2, Ki-67, brain-derived neurotrophic factor (BDNF), vascular endothelial growth factor (VEGF), activity-regulated cytoskeletal protein (Arc), and cAMP response element binding protein (CREB) probes were synthesized by IBA-GmbH (Göttingen, Germany). Details can be found in the Supplementary Information.

Receptor autoradiography. The autoradiographic binding assays for $5-\mathrm{HT}_{1 \mathrm{~A}} \mathrm{R}$, SERT and norepinephrine transporter were performed using the following radioligands: (a) $\left[{ }^{3} \mathrm{H}\right]-8-\mathrm{OH}-D P A T \quad\left(233 \mathrm{Ci} \mathrm{mmol}^{-1}\right), \quad$ (b) $\left[{ }^{3} \mathrm{H}\right]$-citalopram $\left(70 \mathrm{Ci} \mathrm{mmol}^{-1}\right)$ and (c) $\left[{ }^{3} \mathrm{H}\right]$-nisoxetine $\left(85 \mathrm{Cimmol}^{-1}\right)$, respectively (Perkin-Elmer, Madrid, Spain). ${ }^{18,37}$ Experimental conditions are summarized in Supplementary Table S2.

5-HT ${ }_{1 A}$ R-stimulated $\left[{ }^{35}\right.$ S $]$ GTP $\gamma$ S autoradiography. Labeling of DR sections with $\left[{ }^{35} \mathrm{~S}\right] \mathrm{GTP} \gamma \mathrm{S}$ was performed as described previously. ${ }^{38}$ Autoradiograms were analyzed and the relative optical densities (ROD) were obtained using a computer-assisted image analyzer (AIS, Imaging Research, St Catherines, Ontario, Canada). Details are shown in Supplementary information.

5-Bromo-2'-deoxyuridine administration. 5-Bromo-2'deoxyuridine was purchased from Sigma-Aldrich (Madrid, Spain) and dissolved in saline solution. Mice were injected with $4 \times 75 \mathrm{mg} \mathrm{kg}^{-1} 5$-Bromo-2'-deoxyuridine every $2 \mathrm{~h}$, i.p., the last day of antidepressant treatments. Mice were killed $24 \mathrm{~h}$ later.

Immunohistochemistry. Animals were deeply anesthetized with pentobarbital and transcardially perfused with 4\% paraformaldehyde in sodium-phosphate buffer $(\mathrm{pH}=7.4)$. Brains were collected, post-fixed $24 \mathrm{~h}$ at $4{ }^{\circ} \mathrm{C}$ in the same solution, and then placed in gradient sucrose or phosphatebuffered saline $10-30 \%$ for 2 days at $4{ }^{\circ} \mathrm{C}$. After

Figure 1 Serotonin transporter-small interference RNA (SERT-siRNA) treatment, but not fluoxetine (FLX), downregulates SERT mRNA and protein levels. Mice were infused with two-, four- or seven-dose SERT- or nonsense siRNA (ns-siRNA) $(10 \mu \mathrm{g}-0.7 \mathrm{nmol}$ per day) or vehicle into the dorsal raphe nucleus (DR). Other groups of mice were treated with 4,7 or 15 -day FLX ( $20 \mathrm{mg} \mathrm{kg}^{-1}$ per day, intraperitoneally) or saline. (a) Representative coronal brain sections showing reduced SERT expression in the DR of mice treated with SERT-siRNA (four dose), but not with FLX, as assessed by in situ hybridization. Scale bar $=500 \mu \mathrm{m}$. (b) Bar graphs showing no differences in SERT mRNA level in DR and median raphe nucleus (MnR) of FLX-treated mice. However, SERT-siRNA at different doses significantly reduced SERT mRNA level exclusively in DR ( $n=5-10$ mice per group). Two-way analysis of variance revealed a significant effect of group $\left(F_{2,33}=59.32, P<0.001\right)$. (c) Representative images of SERTimmunoreactive (SERT-ir) axons in the hippocampal CA1 region. Short-term SERT-siRNA treatment (four dose) significantly decreased the target SERT protein density as compared with vehicle and ns-siRNA-treated mice. In contrast, FLX treatment did not alter SERT-ir axon density. Box insets represent regions of high-magnification photomicrographs. Scale bars: lower magnification $=100 \mu \mathrm{m}$ and high magnification $=20 \mu \mathrm{m}$. (d) SERT-ir fiber density in different hippocampal subfields including CA1, CA2, CA3 and dentate gyrus (DG) was measured and expressed as the percentage of the density in the respective vehicle-treated mice ( $n=4-6$ mice per group). Two-way ANOVA showed an effect of group $\left(F_{2,11}=11.16, P<0.01\right)$. (e) Local citalopram (SSRI) infusion by reverse dialysis induced a concentration-dependent increase of extracellular 5-HT in caudate putamen (CPu) of vehicle-treated mice $(n=7)$. However, this effect was lesser marked in SERT-siRNA-treated mice $(n=9)$. Two-way ANOVA showed an effect of group $\left(F_{1,14}=17.17, P<0.0001\right)$, concentration $\left(F_{3,42}=27.06, P<0.0001\right)$ and group-by-concentration interaction $\left(F_{3,42}=7.72, P<0.0001\right)$. ${ }^{\star} P<0.05,{ }^{* \star} P<0.01,{ }^{* * *} P<0.001$ compared with vehicle and ns-siRNA-treated mice. Values are mean \pm s.e.m. 
cryopreservation, $30-\mu \mathrm{m}$-thick free-floating coronal brain sections were processed for immunohistochemical visualization of SERT, BdrU, Ki-67, NeuroD, NeuN, Doublecortin (DCX), GFAP and IBA-1 by using the biotin-labeled antibody procedure. Details are shown in Supplementary Information.

Intracerebral microdialysis. Extracellular serotonin concentration was measured by in vivo microdialysis. ${ }^{18,39}$ Details are shown in the Supplementary Information.

Tail suspension test. Mice were moved from the housing room to the testing area in their home cages and allowed to adapt to the new environment for at least $1 \mathrm{~h}$ before testing. Mice were suspended $30 \mathrm{~cm}$ above the bench by adhesive tape placed $\sim 1 \mathrm{~cm}$ from the tip of the tail. The total duration of immobility during a 6 min test was measured.

Statistical analysis. Data are expressed as means \pm s.e.m. Data were analyzed with Student's $t$-test, one- two- or threeway analysis of variance as appropriate followed by post-hoc test (Newman-Keuls). The level of significance was set at $P<0.05$.

\section{Results}

In vivo characterization of SERT knockdown in mice. We first examined the feasibility to acutely suppress in vivo SERT expression in raphe 5-HT neurons using a SERT-siRNA. Mice were locally infused with: (a) vehicle, (b) ns-siRNA or (c) SERT-siRNA (10 $\mu \mathrm{g}$ per dose) into DR for 2 consecutive days using a protocol similar to that inducing $5-\mathrm{HT}_{1 \mathrm{~A}}$-autoreceptor knockdown. ${ }^{18,40}$ Histological analysis revealed a significant decrease of SERT expression in $\mathrm{DR}$-but not in median raphe nucleus $(\mathrm{MnR})$-of SERT-siRNA-treated mice (SERT mRNA and binding levels were $63 \pm 4 \%$ and $70 \pm 8 \%$, respectively versus vehicle and ns-siRNA-treated mice). Neither treatment altered the raphe expression of norepinephrine transporter, $5-\mathrm{HT}_{1 \mathrm{~A}} \mathrm{R}$ and tryptophan hydroxylase 2 (Supplementary Figure S1a-d).
Next, we evaluated the potential neurotoxic effects of SERT-siRNA infusion by immunohistochemical staining for NeuN, GFAP and IBA-1 (neuronal, astrocyte and microglial markers, respectively). Compared with control groups (ns-siRNA and vehicle), SERT-siRNA-treated mice showed no loss of NeuN-positive neurons in DR. In addition, a mild increase in DR GFAP was noted in all experimental groups, likely due to the reactive astrogliosis secondary to the microcannula implant. Likewise, IBA-1-stained sections in each group showed no increase in activated microglia, except for within the injection tracts (Supplementary Figure S2a-c).

The functional impact of siRNA-induced acute SERT reduction was assessed by in vivo microdialysis in caudate putamen $(\mathrm{CPu})$, a forebrain area exclusively innervated by DR 5 -HT fibers. ${ }^{41}$ Local $50 \mu \mathrm{m}$ veratridine application produced a similar increase of extracellular 5-HT in CPu of all groups, indicating that SERT knockdown did not alter the impulsedependent 5-HT release. However, $1 \mu \mathrm{m}$ citalopram (SSRI) infusion by reverse dialysis increased 5 -HT concentration in CPu of vehicle (170 $\pm 27 \%$ of baseline) and ns-siRNA-treated mice $(180 \pm 15 \%)$, but not of SERT-siRNA-treated mice $(83 \pm 8 \%)$, reflecting a decreased SERT expression/function in the latter group (Supplementary Figure S3a). In addition, fluoxetine administration (SSRI; $20 \mathrm{mg} \mathrm{kg}^{-1}$, i.p.) enhanced extracellular 5-HT in $\mathrm{CPu}$ of vehicle-treated mice $(8.0 \pm 1.0 \mathrm{fmol}$ per fraction), reaching the basal values in SERT-siRNA-treated mice (10.0 $\pm 0.6 \mathrm{fmol}$ per fraction) (Supplementary Figure S3b). Next, the efficacy of SERTsiRNA infusion was tested in the tail suspension test, a highly reliable predictor of clinical antidepressant potential. ${ }^{42,43}$ Mice treated with SERT-siRNA showed a significant reduction of the immobility time compared with control groups (Supplementary Figure S3c).

\section{Different regulation of SERT MRNA and protein levels after SERT-siRNA or fluoxetine treatment. Following verification the effectiveness of SERT suppression by acute SERT-siRNA, we evaluated the effect on SERT regulation after short-term SERT-siRNA administration and its time course. Mice were infused intra-DR with four- or seven-dose}

Figure 2 (a-f) Short-term serotonin transporter-small interference RNA (SERT-siRNA) treatment, but not fluoxetine ( $\mathrm{FLX}$ ), reduces 5 - $\mathrm{HT}_{1 \mathrm{~A}}$-autoreceptor expression and function. Mice were infused with four or seven dose SERT- or nonsense siRNA (ns-siRNA; $10 \mu \mathrm{g}$ per day) or vehicle into dorsal raphe nucleus (DR). Other groups of mice were treated with 4, 7 or 15-day FLX ( $20 \mathrm{mg} \mathrm{kg}^{-1}$ per day, intraperitoneally (i.p.) or saline. (a) Representative coronal midbrain sections showing $\left[{ }^{3} \mathrm{H}\right]-8-\mathrm{OH}-\mathrm{DPAT}$ binding to 5 - $\mathrm{HT} \mathrm{T}_{1 \mathrm{~A}} \mathrm{R}$ in DR. The arrow indicates the decreased DR 5- $\mathrm{HT}_{1 \mathrm{~A}} \mathrm{R}$ density in SERT-siRNA-treated mice (four dose). Scale bar $=2 \mathrm{~mm}$. (b) Bar graphs showing no differences in DR 5-HT ${ }_{1 A} R \mathrm{mRNA}$ levels of vehicleand FLX-treated mice. However, SERT-siRNA significantly reduced $5-H T_{1 A} R$ mRNA level in DR compared with vehicle and ns-siRNA groups ( $n=3-5$ mice per group). Two-way analysis of variance (ANOVA) revealed an effect of group $\left(F_{2,15}=22.59, P<0.001\right)$. (c) Quantitative $\left[{ }^{3} \mathrm{H}\right]-8-\mathrm{OH}-\mathrm{DPAT}$ binding showed a decreased $\mathrm{DR} 5-\mathrm{HT} \mathrm{T}_{1 \mathrm{~A}} \mathrm{R}$ density after $\mathrm{SERT}-\mathrm{siRNA}$ treatment, but not with FLX $(n=4-7)$. Two-way ANOVA showed a significant effect of group $\left(F_{2,15}=20.69, P<0.001\right)$. (d) Autoradiograms of coronal midbrain sections of mice showing $5-\mathrm{HT}_{1 \mathrm{~A}} \mathrm{R}$ 8-OH-DPAT agonist-stimulated $\left.{ }^{35} \mathrm{~S}\right] \mathrm{GTP} \gamma \mathrm{S}$ binding. Scale bar $=500 \mu \mathrm{m}$. (e) FLX induced a decreased DR 8-OH-DPAT-stimulated $\left[{ }^{35} \mathrm{~S}\right] \mathrm{GTP} \gamma \mathrm{S}$ binding from days 7 to 15 of treatment $(n=5-8)$. Two-way ANOVA showed an effect of group $\left(F_{3,25}=11.40, P<0.001\right)$. However, SERT-siRNA produced a fast $5-\mathrm{HT}_{1 \mathrm{~A}}$-autoreceptor desensitization detected after four dose treatment $(n=4-8)$. Two-way ANOVA revealed an effect of group $\left(F_{2,31}=10.47, P<0.001\right)$. (f) The 5-HT ${ }_{1 A} R$ agonist 8-OH-DPAT $\left(0.5 \mathrm{mg} \mathrm{kg}^{-1}\right.$, i.p.) decreased extracellular 5 HT concentration in ventral hippocampus (HPC) of saline- and FLX-treated mice (4-day), but not after 15-day FLX treatment $(n=5-9)$. Two-way ANOVA showed an effect of group $\left(F_{2,18}=41.32, P<0.0001\right)$, time $\left(F_{10,180}=13.96, P<0.001\right)$ and interaction $\left(F_{20,180}=4.41, P<0.001\right)$. Similarly, 8-OH-DPAT had no effect on ventral HPC 5-HT release in SERTsiRNA-treated mice (four-dose), unlike to control groups $(n=4)$. Two-way ANOVA showed an effect of group $\left(F_{2,8}=23.13, P<0.0001\right)$, time $\left(F_{10,80}=6.38, P<0.001\right)$ and interaction $\left(F_{20,80}=4.41, P<0.001\right)$. $(\mathrm{g}-\mathrm{h})$ Time course of the increase in extracellular 5 -HT levels in forebrain. Mice received an intra-DR infusion of two or four dose siRNA or vehicle. Microdialysis experiments were performed on the 3rd or 6th day, respectively. In addition, groups of mice were treated with $\mathrm{FLX}\left(20 \mathrm{mg} \mathrm{kg}^{-1}\right.$ per day, i.p.) or saline and microdialysis experiments were performed $24 \mathrm{~h}$ after the last administration on 2nd, 3rd, 4th, 5th, 7th, 8th and 16th day. (g) FLX treatment significantly increased extracellular 5-HT levels in caudate putamen (CPu) from six dose onwards, compared with saline-treated mice $\left(F_{13,80}=7.43, P<0.0001 ; n=7-10\right.$ mice per group). In contrast, SERT-siRNA-treated mice displayed a larger and faster increase in CPu 5-HT levels, which was significantly different from control already after two-dose treatment $\left(F_{5,60}=32.52, P<0.0001 ; n=7-12\right.$ mice per group). (h) Long-term FLX treatment (15 dose) also increased 5-HT levels in ventral HPC compared with saline-treated mice $\left(F_{3,20}=39.93, P<0.0001 ; n=4-9\right)$. SERT-siRNA-treated mice (four dose) also showed a rapid and

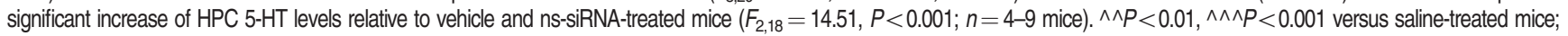
${ }^{\star} P<0.05,{ }^{* \star} P<0.01,{ }^{* \star *} P<0.001$ versus vehicle and ns-siRNA-treated mice. Values are mean \pm s.e.m. 
SERT- or ns-siRNA (10 $\mu \mathrm{g}$ per dose) or vehicle during 5 and 9 days, respectively. The effects on SERT expression were compared with those in mice treated with fluoxetine (20 $\mathrm{mg} \mathrm{kg}^{-1}$ per day, i.p.) or saline for 4,7 or 15 days.

Short-term SERT-siRNA infusion evoked a regionally selective (only in DR) and dose-dependent reduction of SERT mRNA expression. This reduction was not observed in control mice (vehicle and ns-siRNA) nor in any of the fluoxetine-treated groups (Figures $1 a$ and $b$ ). As SERT is localized in the somatodendritic and terminal regions of raphe 5-HT neurons, ${ }^{7}\left[{ }^{3} \mathrm{H}\right]$-citalopram autoradiography was performed to quantify SERT-binding sites in different brain regions along the rostro-caudal axis. Repeated SERT-siRNA infusion, but not ns-siRNA, significantly reduced SERT binding by $\sim 30 \%-40 \%$ in most brain regions analyzed. Differences in the extent of the reduction likely reflect the DR/ $\mathrm{MnR}$ origin of serotonergic fibers in each region (Supplementary Figure S4).

In contrast, a specific $\left[{ }^{3} \mathrm{H}\right]$-citalopram signal was undetectable in fluoxetine-treated mice (4, 7 or 15 days), likely owing to the long half-life of fluoxetine. Additional SERT autoradiography binding was performed in fluoxetine-treated mice (4 or 7-day) and subjected to a 48-96h washout before killed to reduce fluoxetine serum concentrations. ${ }^{13,44}$ Even in these conditions, a specific $\left[{ }^{3} \mathrm{H}\right]$-citalopram binding was not observed (data not shown). a

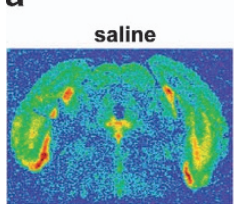

vehicle

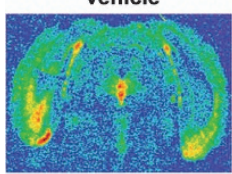

5-HT $1 \mathrm{~A}$ R binding

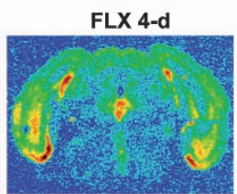

ns-siRNA
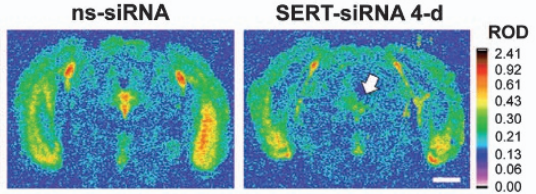

FLX 15-d

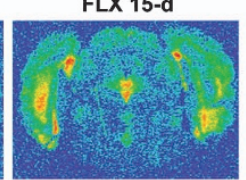

d

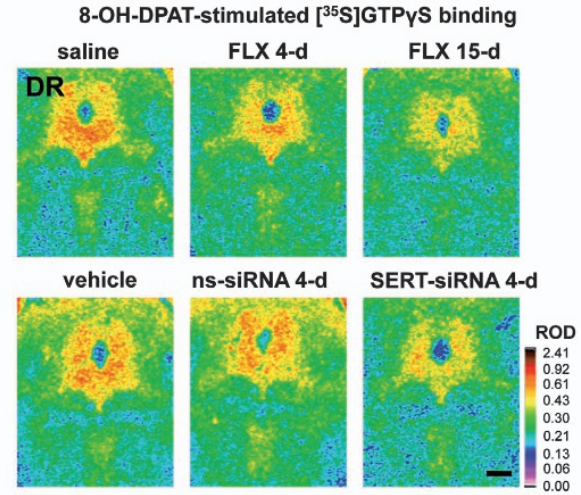

b
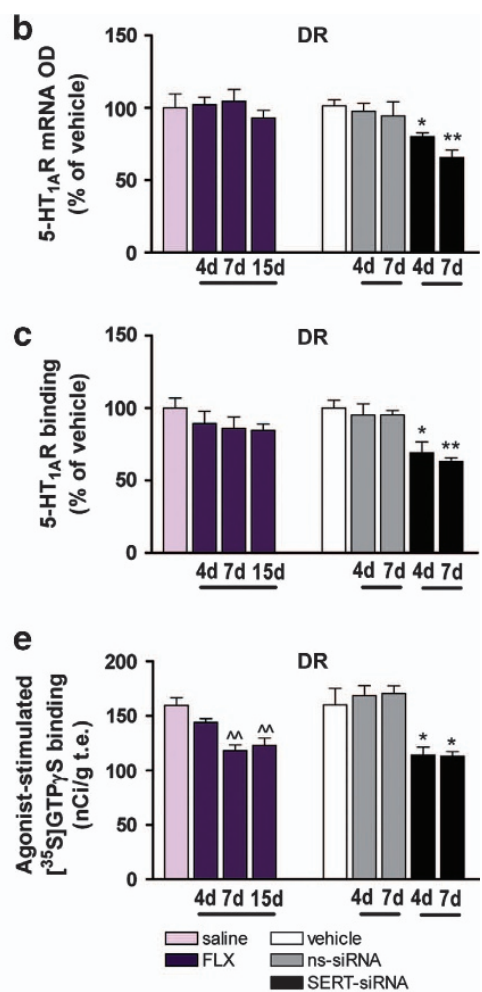
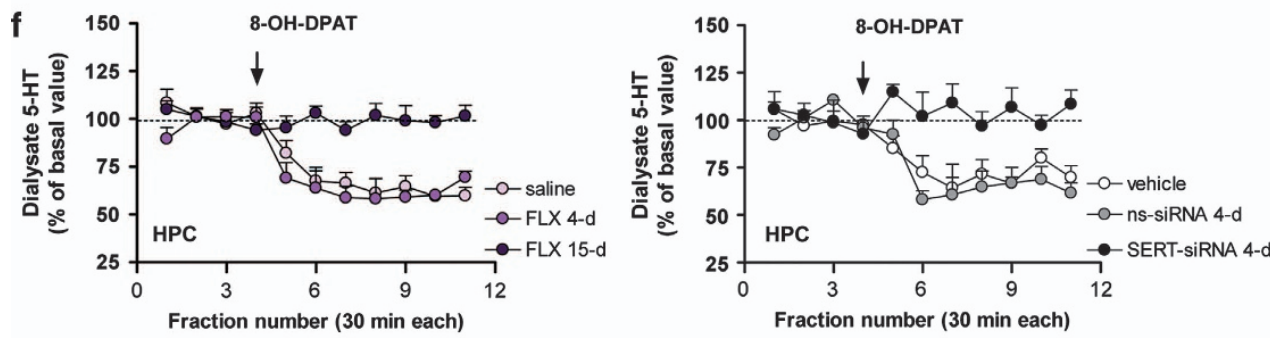

g

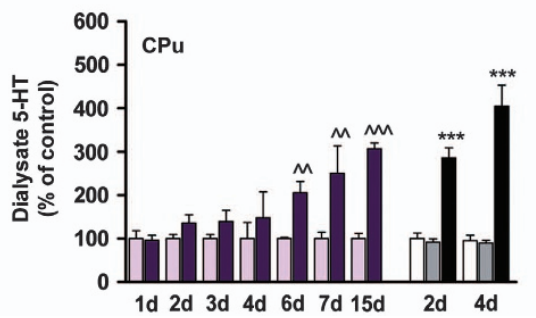

h

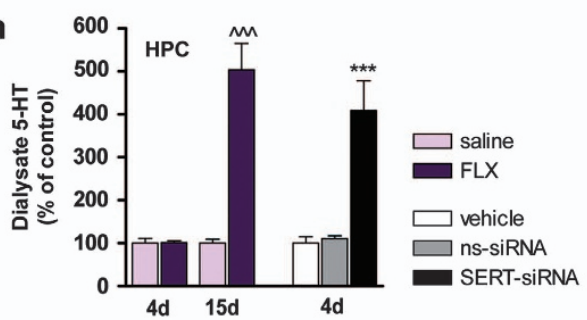


Next, we examined the density of SERT-containing fibers in several brain areas, including different hippocampus (HPC) subfields (Figure 1c and Supplementary Figure S5) where neurogenesis was evaluated (see below). Short-term SERTsiRNA treatment (four dose) caused a rapid and significant decrease of SERT-immunolabeling in different HPC areas relative to vehicle- and ns-siRNA-treated mice. However, SERT-immunolabeling was equal in fluoxetine-treated mice and their respective controls (Figures 1c and d). The presence of an immunohistochemical SERT signal in fluoxetine-treated mice indicates that the lack of specific $\left[{ }^{3} \mathrm{H}\right]$-citalopram binding was due to competence with fluoxetine present in the tissue sections. Likewise, these data highlight the different mechanism of regulation of SERT expression. Thus, whereas SERTsiRNA-induced post-transcriptional changes lead to SERT mRNA knockdown and a subsequent fall in protein density, we did not find an effect of fluoxetine on SERT expression, as previously reported. ${ }^{45,46}$

In agreement with this partial SERT suppression, a decreased SERT function was observed in SERT-siRNAtreated mice (four dose). Hence, local application of citalopram $(1-10-50 \mu \mathrm{m})$ produced much smaller increases of extracellular $5-\mathrm{HT}$ in the $\mathrm{CPu}$ relative to vehicle controls (Figure 1e).

Short-term SERT-siRNA treatment, but not fluoxetine, reduces $5-\mathrm{HT}_{1 \mathrm{~A}}$-autoreceptor expression and function. The functional down-regulation of presynaptic $5-\mathrm{HT}_{1 \mathrm{~A}} \mathrm{R}$ (5$\mathrm{HT}_{1 \mathrm{~A}}$-autoreceptors) is required for the clinical antidepressant action. ${ }^{16,38,47,48}$ Indeed, the degree of $5-\mathrm{HT}_{1 \mathrm{~A}} \mathrm{R}$ mediated inhibition of 5 - HT by SSRIs has been used as a reliable index of their sensitivity. ${ }^{49,50}$ As expected, $5-\mathrm{HT}_{1 \mathrm{~A}^{-}}$ autoreceptor expression was unchanged in any of the fluoxetine-treated groups (Figures $2 a-c$ ). However, 7 and 15-day fluoxetine administration (but not 4-day) attenuated 8$\mathrm{OH}-\mathrm{DPAT}$-stimulated $\left[{ }^{35} \mathrm{~S}\right] \mathrm{GTP} \gamma \mathrm{S}$ binding in the DR, indicating a decrease in G-protein coupling efficiency of $5-\mathrm{HT}_{1 \mathrm{~A}} \mathrm{R}$ (Figures 2d and e). In contrast, a short-term SERT-siRNA treatment significantly reduced $5-\mathrm{HT}_{1 \mathrm{~A}}$-autoreceptor expression and produced a concomitant loss of function as assessed by $\left[{ }^{35} \mathrm{~S}\right] \mathrm{GTP} \gamma \mathrm{S}$ binding (Figures 2a-e).

Likewise, the $5-\mathrm{HT}_{1 \mathrm{~A}} \mathrm{R}$ agonist $8-\mathrm{OH}$-DPAT $\left(0.5 \mathrm{mg} \mathrm{kg}^{-1}\right.$, i.p.) significantly decreased $5-\mathrm{HT}$ release in the HPC of vehicle (62 $\pm 4 \%$ of baseline) and mice treated with fluoxetine for 4 days $(61 \pm 4 \%)$, but not in those treated for 15 days $(99 \pm 2 \%)$ (Figure 2f). Interestingly, 8-OH-DPAT did not reduce hippocampal $5-\mathrm{HT}$ release in four-dose SERT-
siRNA-treated mice ( $103 \pm 5 \%$ of baseline), unlike in control groups (vehicle: $70 \pm 3 \%$ and ns-siRNA: $65 \pm 2 \%$ ) (Figure $2 f$ ). This indicates a very fast attenuation of $5-\mathrm{HT}_{1 \mathrm{~A}}$-autoreceptor sensitivity in SERT-siRNA-treated mice, as observed after long-term pharmacological blockade of SERT. ${ }^{47,51}$

Time course of forebrain extracellular 5-HT concentration after SERT-siRNA or fluoxetine treatment. We next assessed the kinetics of extracellular 5-HT levels after SERT-siRNA or fluoxetine treatment using in vivo microdialysis. Basal extracellular 5-HT levels in CPu and HPC of control mice were: $3.4 \pm 0.3 \mathrm{fmol}$ per fraction $(n=49)$ and $1.7 \pm 0.1 \mathrm{fmol}(n=9)$ per fraction, respectively. Further, baseline 5-HT levels of mice implanted with a silica microcannula into DR were: $3.9 \pm 0.4$ fmol per fraction (CPu, $n=25$ ) and $2.4 \pm 0.5$ fmol per fraction (HPC, $n=10$ ). No significant differences were detected between groups.

Repeated fluoxetine administration induced a progressive and significant increase of 5-HT levels in CPu from days 6 to 15 of treatment compared to their respective saline-treated controls (Figure 2g). SERT-siRNA-treated mice displayed a larger and faster increase in CPu 5-HT levels, which was not seen in control groups. Extracellular $5-\mathrm{HT}$ in $\mathrm{CPu}$ of mice treated with four doses of SERT-siRNA was greater than after 15-day fluoxetine administration (Figure $2 \mathrm{~g}$ ). Similar results were seen in HPC, where SERT-siRNA (four doses) increased extracellular 5-HT to the same extent than a 15day treatment with fluoxetine (Figure $2 \mathrm{~h}$ ). Regional differences are likely owing to the greater contribution of DR axons in $\mathrm{CPu}$ versus HPC. ${ }^{52}$

SERT-siRNA treatment induces faster adult neurogenesis than fluoxetine. We then addressed whether the above temporal differences between SERT-siRNA and fluoxetine translated into the proliferative activity in dentate gyrus (DG), a key feature of antidepressant treatments. To this end, mice were injected with the proliferation marker BdrU on the last day of the antidepressant treatments. Twenty-four hours later, BdrU incorporation was quantified in DG. Remarkably, SERT-siRNA (four dose) significantly enhanced the number of BdrU-labeled cells to $144 \pm 8 \%$ of vehicle-treated mice. No effect was observed in ns-siRNAtreated mice (Figures $3 a$ and b). Detailed morphological analysis revealed that these cells were grouped in clusters, suggesting an acute induction of mitotic activity. Such clusters of BdrU-positive cells were detectable after 15-day (but not 4-day) fluoxetine treatment (BdrU-positive cells:

Figure 3 Serotonin transporter (SERT) silencing accelerates neural proliferation in the adult hippocampus compared with fluoxetine (FLX). Mice were infused with four dose SERT- or nonsense siRNA (ns-siRNA; $10 \mu \mathrm{g}$ per day) or vehicle into dorsal raphe nucleus (DR). Other groups of mice were treated with 4 or $15-$ day FLX (20 mg kg ${ }^{-1}$ per $^{-}$ day, intraperitoneally) or saline. (a) Representative images showing an increased number of 5-Bromo-2'-deoxyuridine (BdrU)-positive cells in the dentate gyrus (DG) of FLXtreated mice (15-day) or serotonin transporter-small interference RNA (SERT-siRNA)-treated mice (four dose) compared with their respective control mice. Box insets frame regions of high-magnification photomicrographs shown below. Scale bars: lower magnification $=100 \mu \mathrm{m}$ and high magnification $=20 \mu \mathrm{m}$. (b) Cell proliferation was assessed by the number of BdrU-positive cells ( $n=5-8$ mice) and Ki-67-positive cells $(n=5-9$ mice) in the granule cell layer. Quantitative analysis indicated a significant increase in both BdrU- and Ki-67-positive cell number for longer treatment with FLX (BdrU: $F_{2,20}=53.16$; Ki-67: $F_{2,17}=20.72$ ) or SERT-siRNA (BdrU: $\left.F_{2,13}=14.10 ; \mathrm{Ki}-67: F_{2,18}=6.26\right)$. (c) Representative coronal brain sections showing Ki-67 expression in DG assessed by in situ hybridization. Scale bar $=100 \mu \mathrm{m}$. (d) Bar graph showing increased Ki-67 mRNA levels in DG following FLX (15-day) and SERT-siRNA (four dose) treatment as compared with respective control groups ( $n=3-4$ mice). One-way analysis of variance revealed a significant effect of group $\left(F_{4,11}=9.73, P<0.01\right) . \wedge P<0.05, \wedge \wedge \wedge P<0.001$ versus saline-treated mice; ${ }^{*} P<0.05,{ }^{*} P<0.01$ versus vehicle and ns-siRNA-treated mice. Values are mean \pm s.e.m. 
$91 \pm 5$ and $229 \pm 16 \%$ following 4- and 15-day fluoxetine relative to saline group) (Figures $3 a$ and $b$ ). Moreover, we confirmed the effects on neural progenitor cell proliferation, assessing the intrinsic Ki-67 expression in DG. ${ }^{53,54}$ Both Ki67 mRNA level and Ki-67-positive cells were significantly increased in the DG of SERT-siRNA- and fluoxetine-treated mice following 4 and 15-day of administration, respectively, compared with their control groups (Figures $3 b-d$ ).

In addition, an increase in NeuroD-positive cells was seen in the subgranular cell layer of DG after four-dose SERT-

a

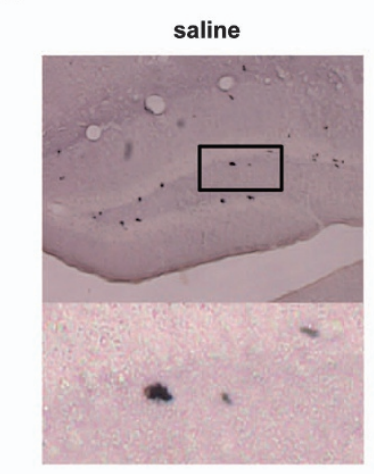

vehicle

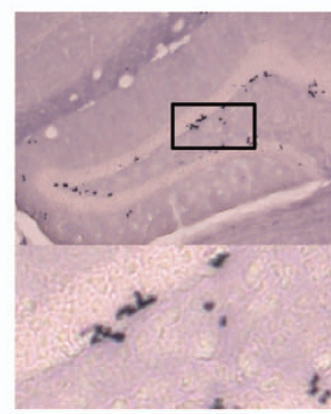

b

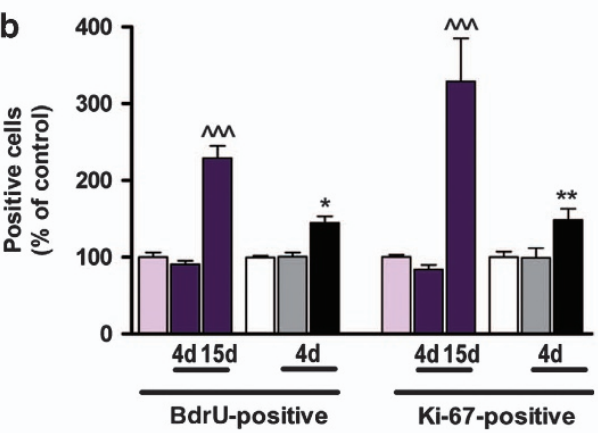

C

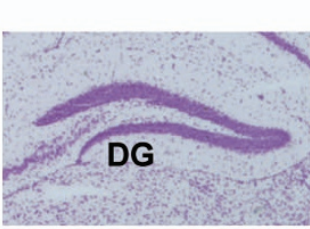

vehicle

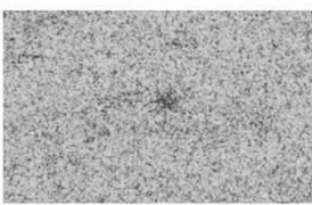

FLX 4-d

ns-siRNA 4-c

saline
BdrU-ir
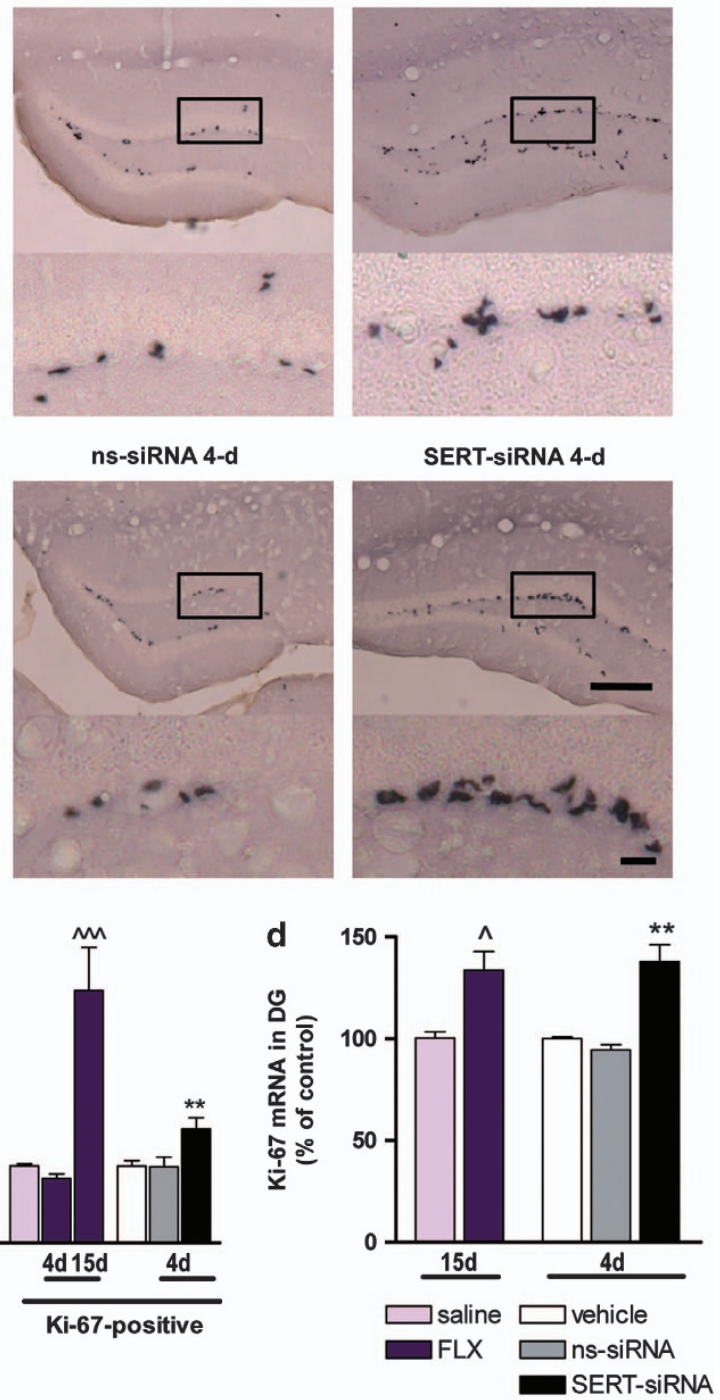

Ki-67 mRNA

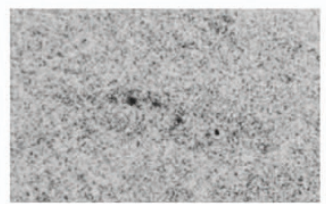

ns-siRNA 4-d

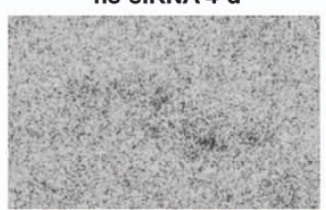

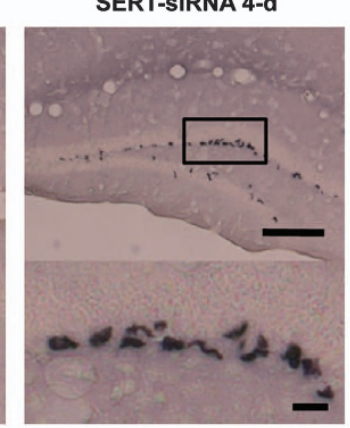

FLX 15-d

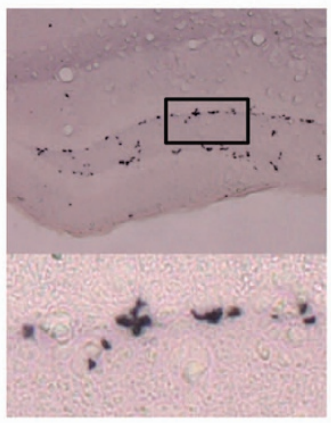

SERT-SIRNA 4-d

FLX 15-d

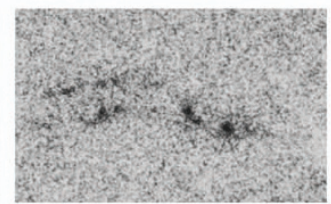

SERT-SIRNA 4-d

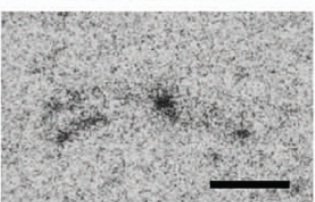


siRNA treatment $(129 \pm 5 \%$ of vehicle), whereas fluoxetine administration (15-day) led to a slight, but non-significant increase in the number of immature neurons (NeuroD-positive cells: $115 \pm 10 \%$ of vehicle) (Figures $4 a$ and b). To assess whether SERT-siRNA regulates neuronal cell migration, DCX-immunostaining was performed. SERT-siRNA treatment (four-dose) significantly enhanced the number of DCXpositive cells in the DG $(137 \pm 9 \%$ of vehicle) compared with control groups. Similar data were obtained after 15-day fluoxetine administration (DCX-positive cells: $121 \pm 4 \%$ of vehicle) (Figures $4 c$ and $d$ ).

\section{Short-term SERT-siRNA treatment, but not fluoxetine, enhances hippocampal plasticity-associated gene} expression. As the final step of the present study, we assessed whether SERT-siRNA (four dose) was able to increase the hippocampal expression of trophic factors such as BDNF and VEGF, which are known to be enhanced only after prolonged (2-3 weeks) antidepressant treatments. ${ }^{55-57}$ We also examined the effects on the expression of the immediate early gene Arc and the transcription factor CREB, which are also regulated by chronic antidepressant treatments and contribute to the antidepressant efficacy. ${ }^{58,59} \mathrm{We}$ found that SERT-siRNA infusion (four dose) robustly and significantly increase BDNF mRNA levels in the different hippocampal areas (CA1: $134 \pm 9 \%$, CA3: $144 \pm 9 \%$ and DG: $122 \pm 2 \%$ of vehicle) (Figure 5a). A 15-day fluoxetine treatment (but not 4-day) increased BDNF mRNA expression only in DG (151 $\pm 25 \%$ ). Likewise, SERT-siRNA (four dose) significantly enhanced VEGF expression in all HPC subfields $(\sim 125 \%)$, as produced by 15 -day fluoxetine treatment (Figure 5b).

Furthermore, SERT-siRNA (four dose) significantly upregulated the Arc mRNA expression in CA1 and DG ( 135\%), an effect that was observed in DG only after 15-day fluoxetine treatment $(190 \pm 27 \%$ ) (Figure $5 \mathrm{c}$ ). In contrast to these changes, neither SERT-siRNA nor fluoxetine altered hippocampal CREB mRNA expression (Figure $5 \mathrm{~d}$ ).

\section{Discussion}

The present study shows that partial RNAi-based reduction of SERT expression in mouse DR has dramatic effects on serotonergic neurotransmission. Short-term SERT-siRNA treatment evoked a number of changes in behavioral, neurochemical and cellular variables predictive of therapeutic antidepressant activity, such as (i) reduced immobility time in the tail suspension test, (ii) increased extracellular 5-HT concentration, (iii) downregulated 5- $\mathrm{HT}_{1 \mathrm{~A}}$-autoreceptor expression/function, (iv) enhanced hippocampal neurogenesis and (v) increased hippocampal expression of plasticity-associated genes. Remarkably, these changes occurred much earlier and were in general of greater magnitude than those evoked by long-term SSRI-fluoxetine administration. Together with earlier reports, ${ }^{18,35,40}$ this study illustrates the therapeutic potential of siRNA-based strategies in the treatment of major depression. In particular, our data highlight the relevance of post-transcriptional SERT regulation as a new therapeutic approach to develop fast-acting antidepressants.

We previously showed that unmodified SiRNA infusion into the mouse DR and also, intracerebroventricular or intranasal administration of a conjugated siRNA can efficiently and selectively reduce $5-\mathrm{HT}_{1 \mathrm{~A}}$-autoreceptor expression in $5-\mathrm{HT}$ neurons, thus evoking antidepressant responses. ${ }^{18,40}$ Here, we suppressed SERT expression, another key mechanism controlling brain serotonergic transmission. RNAi-induced reduction of SERT level triggers remarkable effects on serotonergic function, faster and more efficient than those produced by the pharmacological SERT blockade. Thus, forebrain 5-HT concentration was increased three- and fourfold by two and four doses of SERT-siRNA, respectively, an effect similar to that found after 2-week fluoxetine treatment at a daily dose showing $\sim 90 \%$ SERT occupancy. ${ }^{60}$ The robust effect on extracellular 5-HT, compared with the relatively modest change in SERT expression (consistent with its halflife, $\sim 3$ days), ${ }^{61}$ suggests that functional SERT derives from newly synthesized pools.

As expected from the increased serotonergic function, resulting from the decreased SERT level, mice treated with very small SERT-siRNA $(1.4 \mathrm{nmol})$ showed a marked reduction of immobility in the tail suspension test, a behavioral response evoked by antidepressant drugs. ${ }^{18,42}$ An earlier study also found antidepressant-like effects in the forced swim test but after a prolonged intracerebroventricular SERTsiRNA infusion during 2-week at a higher dose $(31 \mathrm{nmol}$ per day). ${ }^{35}$ Overall, this indicates that SERT knockdown in adulthood significantly improves the resilience to stress, thus contributing to the antidepressant action.

The fast increase of extracellular 5-HT observed in SERT knockdown mice likely accounts for the rapid desensitization of $5-\mathrm{HT}_{1 \mathrm{~A}}$-autoreceptors, a key characteristic of antidepressant drugs. Indeed, $5-\mathrm{HT}_{1 \mathrm{~A}}$-autoreceptor stimulation by the excess 5-HT produced by SSRIs reduces raphe 5-HT neuronal firing and, consequently, 5-HT neurotransmission in forebrain. ${ }^{16}$ Only after successful $5-\mathrm{HT}_{1 \mathrm{~A}}$-autoreceptor desensitization, 5-HT neuron activity and terminal 5-HT release are recovered. ${ }^{17,47}$ In agreement with these previous studies, fluoxetine desensitized $5-\mathrm{HT}_{1 \mathrm{~A}}$-autoreceptors after 2-week treatment. Interestingly, short-term SERT-siRNA

Figure 4 Serotonin transporter (SERT) silencing rapidly increases the number of NeuroD- and DCX-positive cells in hippocampus. Mice were infused with four dose SERT- or nonsense siRNA (ns-siRNA; $10 \mu \mathrm{g}$ per day) or vehicle into dorsal raphe nucleus (DR). Other groups of mice were treated with 4 or 15 -day fluoxetine (FLX; $20 \mathrm{mg} \mathrm{kg}^{-1}$ per day, intraperitoneally) or saline. (a) Immunohistochemical images showing NeuroD-positive progenitors in the dentate gyrus (DG) of mice. Box insets represent regions of high-magnification photomicrographs. Scale bars: lower magnification $=100 \mu \mathrm{m}$ and high magnification $=20 \mu \mathrm{m}$. (b) Quantitative analysis indicated a significant increase in the number of NeuroD-positive cells in serotonin transporter-small interference RNA (SERT-siRNA)-treated mice (four dose) compared with vehicle and ns-siRNA-treated mice ( $n=5-9$ mice). One-way analysis of variance (ANOVA) showed an effect of group $\left(F_{2,11}=5.87, P<0.05\right)$. (c) Representative photomicrographs showing DCX-positive cells, bearing a complex dendritic morphology in the DG of mice. Scale bar $=20 \mu \mathrm{m}$. (d) Quantitative analysis revealed a significant increase in the number of DCX-positive cells in both 15-day $\operatorname{FLX}\left(F_{2,29}=7.71, P<0.01\right)$ and four dose SERT-siRNA-treated mice $\left(F_{2,18}=5.94, P<0.05\right)(n=6-10)$. $\wedge \wedge P<0.01$ versus saline-treated mice; ${ }^{*} P<0.05,{ }^{* *} P<0.01$ versus vehicle and ns-siRNA-treated mice. Values are mean \pm s.e.m. 
a

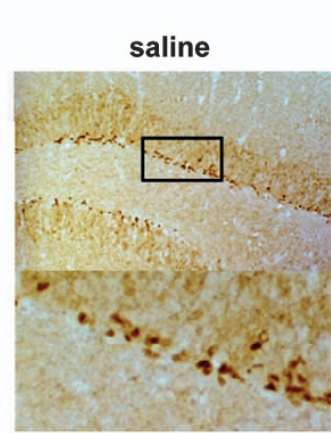

vehicle
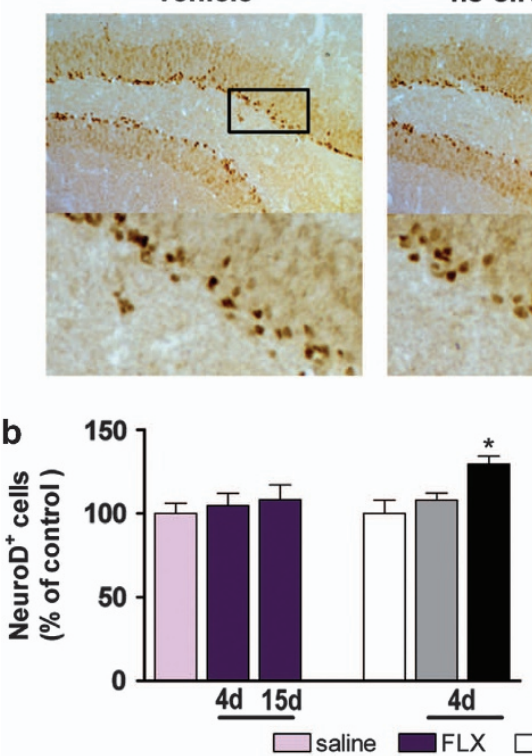

C
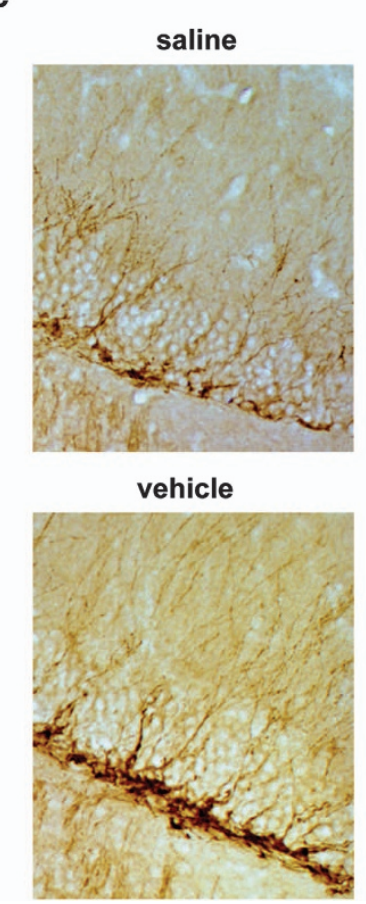

NeuroD-ir

FLX 4-d

ns-siRNA 4-d
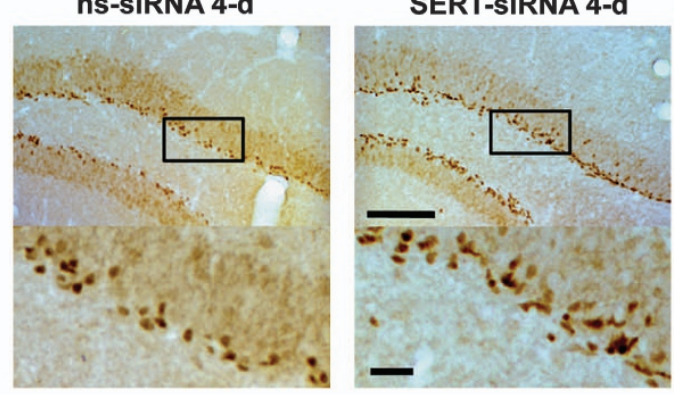

FLX 15-d

SERT-siRNA 4-d
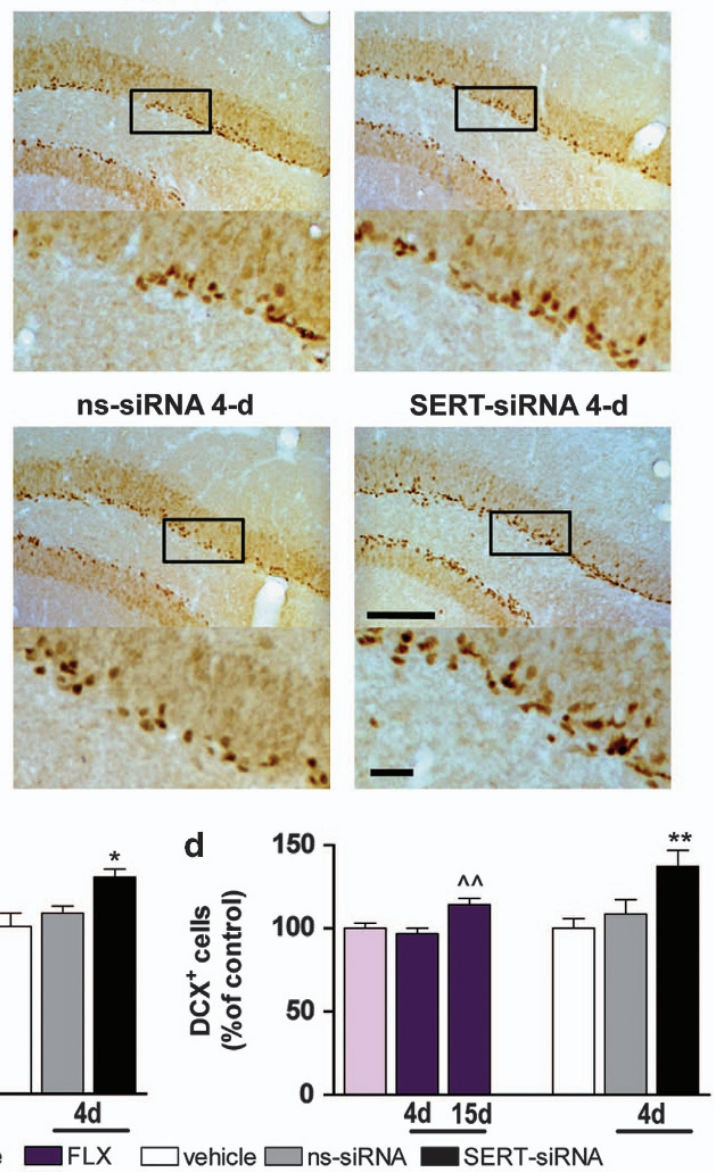

DCX-ir

FLX 4-d

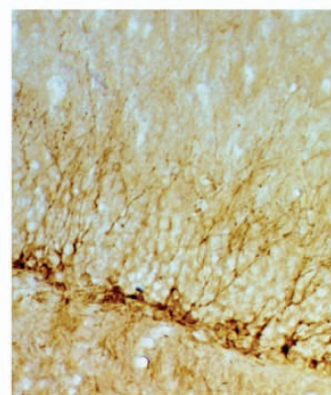

ns-siRNA 4-d

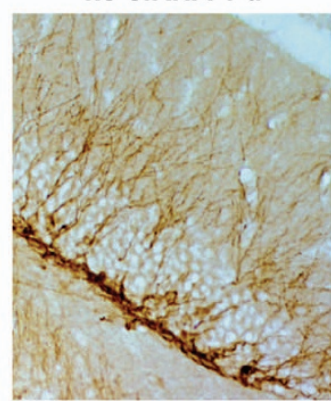

FLX 15-d

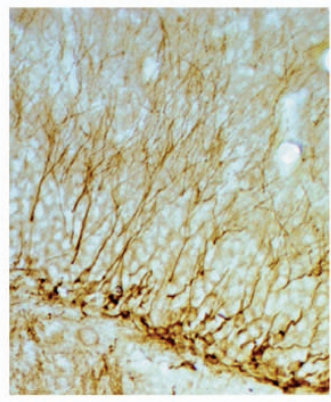

SERT-siRNA 4-d

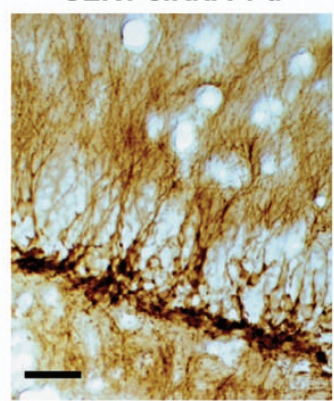


a
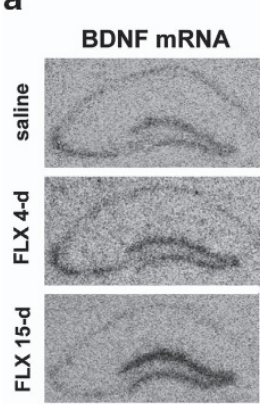

b
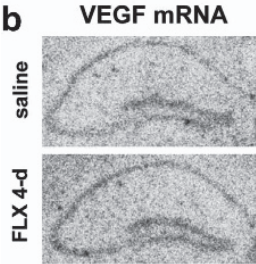

물

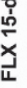

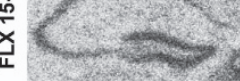

C
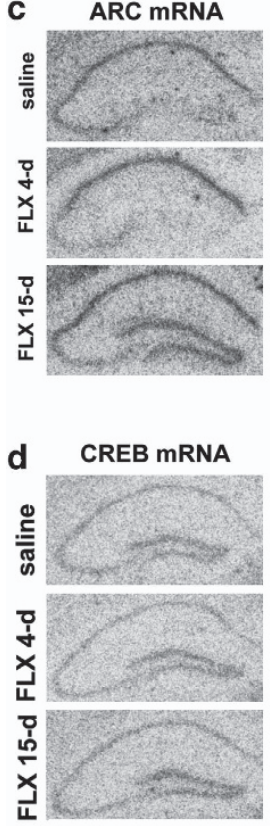
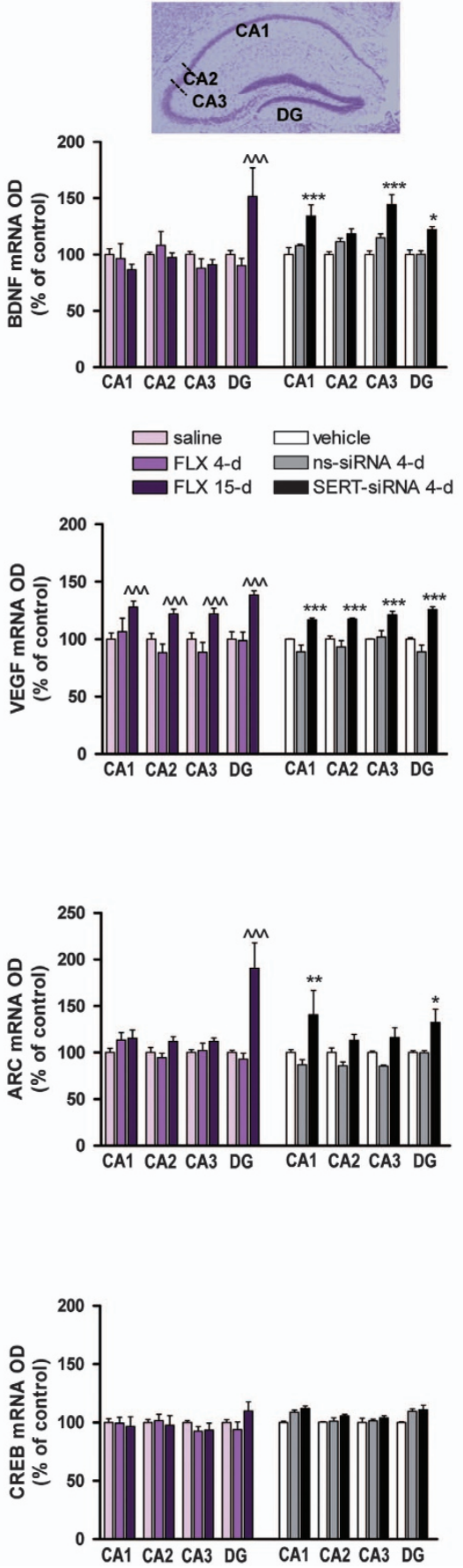
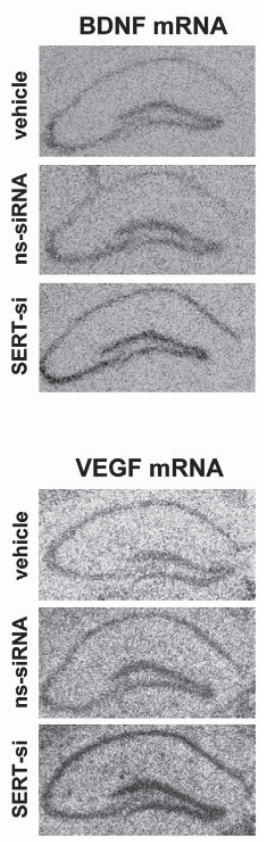

ARC mRNA
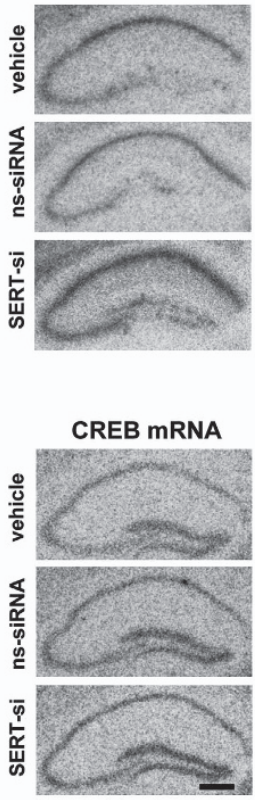

Figure 5 Serotonin transporter (SERT) silencing enhances hippocampal plasticity-associated gene expression. Mice were infused with four dose SERT- or nonsense siRNA (nssiRNA; $10 \mu \mathrm{g}$ per day) or vehicle into dorsal raphe nucleus (DR). Other groups of mice were treated with 4 or 15 -day fluoxetine (FLX; $20 \mathrm{mg} \mathrm{kg}^{-1}$ per day, intraperitoneally) or saline. (a-d) Representative autoradiograms of hippocampal sections of mice are shown for (a) brain-derived neurotrophic factor (BDNF), (b) vascular endothelial growth factor (VEGF), (c) activity-regulated cytoskeletal protein (Arc) and (d) CAMP response element binding protein (CREB) mRNA expression. Scale bar $=100 \mu \mathrm{m}$. Densitometric analyses were performed in different hippocampal regions: CA1, CA2, CA3 and dentate gyrus (DG), shown in the cresyl violet-stained section (top). Levels of mRNA for each gene are shown in the bar graphs next to the representative autoradiograms ( $n=4-5$ mice). (a) BDNF mRNA levels in DG were significantly increased after 15-day FLX treatment compared with saline-treated mice (two-way analysis of variance (ANOVA): effect of region $F_{3,33}=5.76$ and interaction group-by-region $F_{6,33}=7.86$ ). However, serotonin transporter-small interference RNA (SERTsiRNA) treatment (four dose) increased BDNF expression in CA1, CA3 and DG compared with respective control groups (significant effect of group $F_{2,8}=18.03$ and region $F_{3,24}=4.33$ ). (b) VEGF mRNA levels were augmented in all hippocampal subfields after FLX (15-day) or SERT-siRNA (four dose) treatments compared with respective control groups (two-way ANOVA; FLX: effect of group $F_{2,10}=10.11$, region $F_{3,30}=12.80$ and interaction $F_{6,30}=4.54$; SERT-siRNA: effect of group $F_{2,8}=17.32$, region $F_{3,24}=5.00$ and interaction $\left.F_{6,24}=5.42\right)$. (c) Arc mRNA levels in DG were significantly increased following FLX (15-day) compared with saline-treated mice (two-way ANOVA: effect of group $F_{2,11}=9.30$, region $F_{3,33}=4.93$ and interaction group-by-region $F_{6,33}=7.75$ ). SERT-siRNA treatment (four dose) increased Arc expression in CA1 and DG compared with respective control groups (significant effect of group $F_{2,13}=11.53$, region $F_{3,39}=6.77$ and interaction $F_{6,39}=4.05$ ). (d) CREB mRNA levels were unchanged following any treatment. $M P<0.001$ versus saline-treated mice; ${ }^{\star} P<0.05,{ }^{\star \star} P<0.01,{ }^{* \star *} P<0.001$ versus vehicle and ns-siRNA-treated mice. Values are mean \pm s.e.m. 
treatment fully disrupts the $5-\mathrm{HT}_{1 \mathrm{~A}}$-autoreceptor function and-unlike fluoxetine-decreases their expression in DR, thus hastening the adaptive presynaptic mechanisms in serotonergic neurotransmission.

The fast-acting antidepressant potential of SERT-siRNA was further confirmed by its ability to increase neurogenesis and to activate the expression of plasticity gene in the adult mouse HPC. It is well accepted that antidepressants share the common property to positively modulate cellular growth and plasticity in mood-related brain areas. Indeed, plasticityassociated gene expression and neurogenesis are considered to be specific markers of antidepressant action. ${ }^{56-59}$ However, these effects require prolonged (for example, $>2$ weeks) administration of antidepressants drugs. ${ }^{62-64}$ One of the more relevant findings of the present study is the observation that short-term SERT-siRNA treatment increased hippocampal progenitor proliferation using two different markers (5-Bromo-2'-deoxyuridine and Ki-67), an effect produced only after 15-day pharmacological SERT blockade. This was accompanied by an increase in the number of NeuroD- and DCX-positive cells, whose morphological complexity suggests that the integration of immature neurons into hippocampal networks may be accelerated by SERT-siRNA. In parallel, SERT-siRNA ( four dose)-but not fluoxetine-, also enhanced the expression of trophic factors such as BDNF and VEGF, as well as that of the activity-dependent Arc gene in several HPC subfields. Neuronal activity recruits latent stem/progenitor cells in the adult HPC, increasing the expression of trophic factors. ${ }^{65}$ Therefore, these could serve to link neuronal activity to structural plasticity in the hippocampal neurogenic niche. Future experiments will examine whether this neurogenic effect is required for the antidepressant-like responses elicited by SERT-siRNA treatment.

In conclusion, our results show that siRNA-induced selective SERT knockdown evokes a number of behavioral, neurochemical and cellular responses predictive of clinical antidepressant activity. Notably, these effects occur after short-term SERT-siRNA treatment and are remarkably faster and-in most instances-more effective than those elicited by persistent SERT blockade with the SSRI fluoxetine. Together with previous observations, ${ }^{18,35,40}$ the present data support the usefulness of RNAi strategies, stimulating serotonergic transmission as a new therapeutic class overcoming the two main limitations of current pharmacological treatments, that is, limited efficacy and slowness of action.

\section{Conflict of interest}

FA has received consulting and educational honoraria on antidepressant drugs from Eli Lilly and Lundbeck. AM is a cofounder and board member of nLife Therapeutics S.L. MCC is an employee of nLife Therapeutics S.L. The rest of authors report no biomedical financial interests or potential conflicts of interest.

Acknowledgements. This research was supported by grants from Spanish Ministry of Science and Innovation-CDTI, with the participation of the DENDRIA Consortium; from Instituto de Salud Carlos III PI10/00290 and Centro de Investigación Biomédica en Red de Salud Mental (CIBERSAM, P91C). Structural funds of the European Union, through the National Applied Research Projects $(R+D+\mid$ 2008/11) and from the Catalan Government (grant 2009SGR220) are also acknowledged. We gratefully thank to Mireia Galofré and Esther Ruiz-Bronchal for technical support and, Anna Castañé for advice in behavioral test.

1. Kessler RC, Chiu WT, Demler O, Merikangas KR, Walters EE. Prevalence, severity, and comorbidity of 12-month DSM-IV disorders in the National Comorbidity Survey Replication. Arch Gen Psychiatry 2005; 62: 617-627.

2. Krishnan V, Nestler EJ. The molecular neurobiology of depression. Nature 2008; 455 : 894-902.

3. Smith K. Trillion-dollar brain drain. Nature 2011; 478: 15.

4. Wong ML, Licinio J. Research and treatment approaches to depression. Nature Rev Neurosci 2001; 2: 343-351.

5. Rush AJ, Trivedi MH, Wisniewski SR, Nierenberg AA, Stewart JW, Warden D et al. Acute and longer-term outcomes in depressed outpatients requiring one or several treatment steps: a STAR*D report. Am J Psychiatry 2006; 163: 1905-1917.

6. Trivedi MH, Fava M, Wisniewski SR, Thase ME, Quitkin F, Warden D et al. Medication augmentation after the failure of SSRls for depression. N Engl J Med 2006; 354: 1243-1252.

7. Blakely RD, De Felice LJ, Hartzell HC. Molecular physiology of norepinephrine and serotonin transporters. J Exp Biol 1994; 196: 263-281.

8. Pickel VM, Chan J. Ultrastructural localization of the serotonin transporter in limbic and motor compartments of the nucleus accumbens. J Neurosci 1999; 19: 7356-7366.

9. Quin Y, Melikian HE, Rye DB, Levey Al, Blakely RD. Identification and characterization of antidepressant-sensitive serotonin transporter proteins using site-specific antibodies. J Neurosci 1995; 15: 1261-1274.

10. Torres GE, Gainetdinov RR, Caron MG. Plasma membrane monoamine transporters: structure, regulation and function. Nature Rev Neurosci 2003; 4: 13-25.

11. Baudry A, Mouillet-Richard S, Schneider B, Launay JM, Kellermann O. miR-16 targets the serotonin transporter: a new facet for adaptive responses to antidepressants. Science 2010; 329: 1537-1541.

12. Benmansour S, Cecchi M, Morilak DA, Gerhardt GA, Javors MA, Gould GG et al. Effects of chronic antidepressant treatments on serotonin transporter function, density, and mRNA level. J Neurosci 1999; 19: 10494-10501.

13. Benmansour S, Owens WA, Cecchi M, Morilak DA, Frazer A. Serotonin clearance in vivo is altered to a greater extent by antidepressant-induced downregulation of the serotonin transporter than by acute blockade of this transporter. J Neurosci 2002; 22: 6766-6772.

14. Lau T, Horschitz S, Berger S, Bartsch D, Schloss P. Antidepressant-induced internalization of the serotonin transporter in serotonergic neurons. FASEB J 2008; 22: 1702-1714.

15. Piñeyro G, Blier $P$, Dennis $T$, de Montigny $C$. Desensitization of the neuronal $5-H T$ carrier following its long-term blockade. J Neurosci 1994; 14: 3036-3047.

16. Artigas $F$, Celada $P$, Laruelle $M$, Adell $A$. How does pindolol improve antidepressant action? Trends Pharmacol Sci 2001; 22: 224-228.

17. Blier $\mathrm{P}$, de Montigny $\mathrm{C}$. Current advances and trends in the treatment of depression. Trends Pharmacol Sci 1994; 15: 220-226.

18. Bortolozzi A, Castañé A, Semakova J, Santana N, Alvarado G, Cortés R et al. Selective siRNA-mediated suppression of $5-\mathrm{HT}_{1 \mathrm{~A}}$ autoreceptors evokes strong anti-depressant-like effects. Mol Psychiatry 2012; 17: 612-623.

19. Frazer A, Benmansour S. Delayed pharmacological effects of antidepressants. Mol Psychiatry 2002; 7: S23-S28.

20. Zhao Z, Zhang HT, Bootzin E, Millan MJ, O'Donnel JM. Association of changes in norepinephrine and serotonin transporter expression with the long-term behavioral effects of antidepressant drugs. Neuropsychopharmacology 2009; 34: 1467-1481.

21. Anguelova M, Benkelfat C, Turecki G. A systematic review of association studies investigating genes coding for serotonin receptors and the serotonin transporter: II. Suicidal behavior. Mol Psychiatry 2003; 8: 646-653.

22. Caspi A, Sugden K, Moffitt TE, Taylor A, Craig IW, Harrington $\mathrm{H}$ et al. Influence of life stress on depression: moderation by a polymorphism in the 5-HTT gene. Science 2003; 301: 386-389.

23. Hu XZ, Lipsky RH, Zhu G, Akhtar LA, Taubman J, Greenberg BD et al. Serotonin transporter promoter gain-of-function genotypes are linked to obsessive compulsive disorder. Am J Hum Genet 2006; 78: 815-826.

24. Lesch KP, Bengel D, Heils A, Sabol SZ, Greenberg BD, Petri S et al. Association of anxiety-related traits with a polymorphism in the serotonin transporter gene regulatory region. Science 1996; 274: 1527-1531.

25. Murphy DL, Lesch KP. Targeting the murine serotonin transporter: insights into human neurobiology. Nat Rev Neurosci 2008; 9: 85-96.

26. Smeraldi E, Zanardi R, Benedetti F, Di Bella D, Perez J, Catalano M. Polymorphism within the promoter of the serotonin transporter gene and antidepressant efficacy of fluvoxamine. Mol Psychiatry 1998; 3: 508-511.

27. Zanardi R, Serretti A, Rossini D, Franchini L, Cusin C, Lattuada E et al. Factors affecting fluvoxamine antidepressant activity: influence of pindolol and 5-HTTLPR in delusional and nondelusional depression. Biol Psychiatry 2001; 50: 323-330.

28. Holmes A, Yang RJ, Murphy DL, Crawley JN. Evaluation of antidepressant-related behavioral responses in mice lacking the serotonin transporter. Neuropsychopharmacology 2002; 27: 914-923 
29. Lira A, Zhou M, Castanon N, Ansorge MS, Gordon JA, Francis JH et al. Altered depressionrelated behaviors and functional changes in the dorsal raphe nucleus of serotonin transporter-deficient mice. Biol Psychiatry 2003; 54: 960-971.

30. Ansorge MS, Zhou M, Lira A, Hen R, Gingrich JA. Early-life blockade of the 5-HT transporter alters emotional behavior in adult mice. Science 2004; 306: 879-881.

31. Holmes A, Murphy DL, Crawley JN. Abnormal behavioral phenotypes of serotonin transporter knockout mice: parallels with human anxiety and depression. Biol Psychiatry 2003; 54: 953-959

32. Oh JE, Zupan B, Gross S, Toth M. Paradoxical anxiogenic response of juvenile mice to fluoxetine. Neuropsychopharmacology 2009; 34: 2197-2207.

33. Davidson BL, Boudreau RL. RNA interference: a tool for querying nervous system function and an emerging therapy. Neuron 2007; 53: 781-788.

34. He L, Hannon GJ. MicroRNAs: small RNAs with a big role in gene regulation. Nat Rev Genet 2004; 5: 522-531.

35. Thakker DR, Natt F, Hüsken D, van der Putten H, Maier R, Hoyer D et al. siRNA-mediated knockdown of the serotonin transporter in the adult mouse brain. Mol Psychiatry 2005; 10: 782-789.

36. Franklin KBJ, Paxinos G. The Mouse Brain in Stereotaxic Coordinates. Academic Press: New York, USA, 2008.

37. Hebert C, Habimana A, Elie R, Reader TA. Effects of chronic antidepressant treatments on 5-HT and NA transporters in rat brain: an autoradiographic study. Neurochem Int 2001; 38 : 63-74.

38. Castro ME, Díaz A, Del Olmo E, Pazos A. Chronic fluoxetine induces opposite changes in $\mathrm{G}$-protein coupling at pre and postsynaptic $5-\mathrm{HT}_{1 \mathrm{~A}}$ receptors in rat brain. Neuropharmacology 2003; 4: 93-101.

39. Amargós-Bosch M, Bortolozzi A, Puig MV, Serrats J, Adell A, Celada P et al. Coexpression and in vivo interaction of serotonin $1 A$ and serotonin2A receptors in pyramidal neurons of prefrontal cortex. Cerebral Cortex 2004; 14: 281-299.

40. Ferrés-Coy A, Santana N, Castañé A, Cortés R, Carmona MC, Toth M et al. Acute 5-HT1A autoreceptor knockdown increases antidepressant responses and serotonin release in stressful conditions. Psychopharmacology (Berl) advance online publication, 21 July 2012 (e-pub ahead of print); PMID:22820867.

41. Azmitia EC, Segal M. An autoradiographic analysis of the differential ascending projections of the dorsal and median raphe nuclei in the rat. J Comp Neurol 1978; 179: 641-667.

42. Cryan JF, Mombereau C, Vassout A. The tail suspension test as a model for assessing antidepressant activity: review of pharmacological and genetic studies in mice. Neurosci Biobehav Rev 2005; 29: 571-625.

43. Nestler EJ, Gould E, Manji H, Buncan M, Duman RS, Greshenfeld HK et al. Preclinical models: status of basic research in depression. Biol Psychiatry 2002; 52: 503-528.

44. Hirano K, Kimura R, Sugimoto Y, Yamada J, Uchida S, Kato Y et al. Relationship between brain serotonin transporter binding, plasma concentration and behavioural effect of selective serotonin reuptake inhibitors. Br J Pharmacol 2005; 144: 695-702.

45. Ramamoorthy S, Blakely RD. Phosphorylation and sequestration of serotonin transporters differentially modulated by psychostimulants. Science 1999; 285: 763-766.

46. Samuvel DJ, Jayanthi LD, Bhat NR, Ramamoorthy S. A role of for p38 mitogen-activated protein kinase in the regulation of the serotonin transporter: evidence for distinct cellular mechanisms involved in transporter surface expression. J Neurosci 2005; 25: 29-41.

47. Artigas F, Romero L, de Montigny C, Blier P. Acceleration of the effect of selected antidepressant drugs in major depression by $5-\mathrm{HT}_{1 \mathrm{~A}}$ antagonists. Trends Neurosci 1996; 19: 378-383.

48. Hensler JG. Differential regulation of $5-\mathrm{HT}_{1 \mathrm{~A}}$ receptor-G protein interactions in brain following chronic antidepressant administration. Neuropsychopharmacology 2002; 26 565-573.
49. Arborelius L, Hawks BW, Owens MJ, Plotsky PM, Nemeroff CB. Increased responsiveness of presumed 5-HT cells to citalopram in adult rats subjected to prolonged maternal separation relative to brief separation. Psychopharmacology 2004; 176: 248-255.

50. Romero L, Artigas F. Preferential potentiation of the effects of serotonin uptake inhibitors by $5-\mathrm{HT}_{1 \mathrm{~A}}$ receptor antagonists in the dorsal raphe pathway: role of somatodendritic autoreceptors. J Neurochem 1997; 68: 2593-2603.

51. Piñeyro G, Blier P. Autoregulation of serotonin neurons: role in antidepressant drug action. Neuropsychopharmacology 1999; 21: 91S-98S.

52. McQuade R, Sharp T. Functional mapping of dorsal and median raphe 5hydroxytryptamine pathways in forebrain of the rat using microdialysis. $J$ Neurochem 1997; 69: 791-796.

53. Kee N, Sivalingam S, Boonstra R, Wojtowicz JM. The utility of Ki-67 and BrdU as proliferative markers of adult neurogenesis. J Neurosci Methods 2002; 115: 97-105.

54. Scholzen T, Gerdes J. The Ki-67 protein: from the known and the unknown. J Cell Physiol 2000; 182: 311-322

55. Dias BG, Banerjee SB, Duman RS, Vaidya VA. Differential regulation of brain derived neurotrophic factor transcripts by antidepressant treatments in the adult rat brain. Neuropharmacology 2003; 45: 553-563.

56. Nibuya M, Morinobu S, Duman RS. Regulation of BDNF and trkB mRNA in rat brain by chronic electroconvulsive seizure and antidepressant drug treatments. J Neurosci 1995; 15: $7539-7547$

57. Warner-Schmidt JL, Duman RS. VEGF is an essential mediator of the neurogenic and behavioral actions of antidepressants. Proc Natl Acad Sci USA 2007; 104 4647-4652.

58. Nibuya M, Nestler EJ, Duman RS. Chronic antidepressant administration increases the expression of cAMP response element binding protein (CREB) in rat hippocampus. J Neurosci 1996; 16: 2365-2372.

59. Pei Q, Zetterström TS, Sprakes M, Tordera R, Sharp T. Antidepressant drug treatment induces Arc gene expression in the rat brain. Neuroscience 2003; 121: 975-982.

60. Wong DT, Bysmaster FP, Reid LR, Fuller RW, Perry KW. Inhibition of serotonin uptake by optical isomers of fluoxetine. Drug Dev Res 1985; 6: 397-403.

61. Kimmel H, Vicentic A, Kuhar MJ. Neurotransmitter transporters synthesis and degradation rates. Life Sci 2001; 68: 2181-2185.

62. Sahay A, Hen R. Adult hippocampal neurogenesis in depression. Nat Neurosci 2007; 10 1110-1115.

63. Santarelli L, Saxe M, Gross C, Surget A, Battaglia F, Dulawa S et al. Requirement of.hippocampal neurogenesis for the behavioral effects of antidepressants. Science 2003; 301: 805-809.

64. Schmidt HD, Duman RS. The role of neurotrophic factors in adult hippocampal neurogenesis, antidepressant treatments and animal models of depressive-like behavior. Behav Pharmacol 2007; 18: 391-418.

65. Walker TL, White A, Black DM, Wallace RH, Sah P, Bartlett PF. Latent stem and progenitor cells in the hippocampus are activated by neural excitation. J Neurosci 2008; 28 5240-5247.

Translational Psychiatry is an open-access journal published by Nature Publishing Group. This work is licensed under the Creative Commons Attribution-NonCommercial-No Derivative Works 3.0 Unported License. To view a copy of this license, visit http://creativecommons.org/licenses/by-nc-nd/3.0/ 